\title{
Effects of operating conditions on cell performance of PEM fuel cells with conventional or interdigitated flow field
}

\author{
Wei-Mon Yan ${ }^{\mathrm{a}, *}$, Chi-Yen Chen ${ }^{\mathrm{a}}$, Sheng-Chin Mei ${ }^{\mathrm{a}}$, Chyi-Yeou Soong ${ }^{\mathrm{b}}$, Falin Chen ${ }^{\mathrm{c}}$ \\ ${ }^{a}$ Department of Mechatronic Engineering, Huafan University, Shih-Ting, Taipei 223, Taiwan \\ ${ }^{\mathrm{b}}$ Department of Aerospace and Systems Engineering, Feng Chia University, Seatwen, Taichung 407, Taiwan \\ ${ }^{\mathrm{c}}$ Institute of Applied Mechanics, National Taiwan University, Taipei 106, Taiwan \\ Received 19 June 2006; received in revised form 25 July 2006; accepted 25 July 2006 \\ Available online 28 August 2006
}

\begin{abstract}
In this work, the influences of various operating conditions including cathode inlet gas flow rate, cathode inlet humidification temperature, cell temperature, etc. on the performance of proton exchange membrane (PEM) fuel cells with conventional flow field and interdigitated flow field are experimentally studied. Experimental results show that the cell performance is enhanced with increases in cathode inlet gas flow rate, cathode humidification temperature and cell temperature. However, as cell temperature is higher than or equal to anode humidification temperature, the cell performance is deteriorated due to failure in humidification of the cell. Comparison between interdigitated flow field and conventional flow field shows that the former provides higher cell performance and remarkably reduces fuel consumption for efficient diffusion of the fuel gas to the diffuser layer. As air is used as the cathode inlet gas, PEM fuel cell with interdigitated flow field can obtain preferable limiting current density, and the optimal power is about 1.4 times as that of the cells with conventional flow field. Rib and shoulder areas are more advantageous to electrochemical reaction in interdigitated flow field; hence a large flow field area ratio degrades the better performance area and thus the cell performance. But too small flow field area ratio also deteriorates the cell performance due to the decrease in effective reaction area. Theoretically, the flow field area has an optimum value, i.e., $50.75 \%$ in this work, providing higher performance than $66.67 \%$.
\end{abstract}

(C) 2006 Elsevier B.V. All rights reserved.

Keywords: Proton exchange membrane fuel cell; Flow field design; Interdigitated flow field; Performance test

\section{Introduction}

In proton exchange membrane (PEM) fuel cell, it is an important issue to get the reactant gas effectively and homogeneously transported to catalyst layer for reaction. To this end, the most direct method is to appropriately design the flow field. Hentall et al. [1] employed graphite (conventional), aluminum, titanium, stainless steel and graphite (Grafoil ${ }^{\mathrm{TM}}$ ) as the materials of the bipolar plate to analyze the influences of various materials on the fuel cell performance. Results indicated that there was an optimal width ratio of flow channel-to-rib. Nguyen [2] and Wood et al. [3] investigated on the influences of interdigitated and conventional flow fields on the cell performance, as well as reactant mass transport rate, membrane humidification condition and

\footnotetext{
* Corresponding author. Tel.: +886 26632102; fax: +886226632143.

E-mail address: wmyan@ @uafan.hfu.edu.tw (W.-M. Yan).
}

water content, etc. Results showed that, with conventional flow field, liquid water would accumulate on the cathode side and cause the degradation in cell performance; while in interdigitated flow field, water generated by reaction and electro-osmosis was effectively removed, and at high current density interdigitated flow field designs could ameliorate mass transport deficiency, increase PEM hydration and conductivity, delay the occurrence of limit current density and lead to an efficiency enhancement by a factor of 30-100\%. He et al. [4] and Yi and Nguyen [5] simulated the flow field in interdigitated channel of the cathode and explored the influences of cathode electrode thickness, flow channel number, shoulder width and pressure on the cell performance. Numerical results indicated that current density increased with a higher pressure, which implied that an increase in stoichiometric oxygen flow rate was required. By increasing the number of the flow channels, gas flow rate through the shoulder area and oxygen concentration at the reaction interface can be enhanced. In addition, with the increasing width ratio of flow 
channel to shoulder, gas through shoulder area was increased due to a decrease in the cell internal resistance.

By increasing the operating time and electric current, water and thermal management becomes progressively more important. Nguyen and White [6] analyzed the influences of humidification on water and thermal management in PEM fuel cells. Results showed that in downstream part of the flow field, less water was held by the membrane, and electro-osmosis coefficient and ionic conduction were lower, which implied lower fuel consumption and thereby lower cell performance. Choi et al. [7] dealt with the effects of cathode humidification and found that, with humidification, cathode absorption was predominant over electro-osmosis at low current density and the water contained in the membrane was mainly from the cathode. But with the increasing current density and/or decreasing electro-osmosis drag coefficient, water supply to the anode side of the membrane was enhanced. Li et al. [8] and Um and Wang [9] analyzed the relation between mass transport and electrochemical reaction in PEMFC by three-dimensional simulation. They found that the gas fuel humidification conditions had significant impact on the output voltage at high current density, but over-high humidification would increase water content inside the flow field, which caused a reduction in effective reactive area and degradation in cell performance. In interdigitated flow field, however, strong forced convection enhanced the efficiency of liquid water removal and the reaction current density as well.

In PEM fuel cell operation, besides appropriate water and thermal management, reactant gas transport in the fuel cell is also one of the major factors that influence the overall cell performance. Kazim et al. [10] numerically simulated the differences in limit current density and the maximum power density between conventional and interdigitated flow fields. Numerical predictions showed that, despite pressure loss in interdigitated flow field, its limit current density was three times of the value for a conventional parallel flow field. Hontanon et al. [11] numerically analyzed the influences of different permeability between conventional flow channel and porous material on hydrogen consumption rate, pressure drop and cell performance. Their results showed that in conventional flow channels, variation of flow channel-to-rib width ratio affected the anode side hydrogen consumption and effective electrode reactive area. But by decreasing flow channel width and flow channel number, together with increasing rib width, the anode hydrogen consumption was increased, with gas distribution homogeneity improved, resulting in enhanced PEM fuel cell performance. Dutta et al. [12] and Nguyen et al. [13] studied PEM fuel cell gas transport in serpentine flow field. Results indicated that current density distribution would not be restricted in low-load condition due to oxygen diffusion, resulting in higher current density near the collector electrode; as load increased, however, the restriction effect on oxygen transport near the collector electrode became increasingly more significant and lead to an enhancement of oxygen concentration and high current density in the flow channel. Dohle et al. [14] and Yan et al. [15] analyzed how PEM fuel cell performance was influenced by gas flow distribution, the diffuser layer shape, oxygen consumption along the gas channel, and gas transport from flow channel to the gas diffuser layer.
Results indicated that for a long channel, the fuel in downstream part of the flow field may become insufficient, and the effective work area was accordingly reduced, and the limit current density may appear early. By increasing flow channel width ratio and flow channel number, oxygen was distributed in the flow field more homogeneously, and fuel consumption was accordingly increased. As a consequence, the electrochemical reaction and therefore the cell performance can be enhanced. Kumar and Reddy [16] explored the influences of flow field sizes and shapes on fuel gas distribution and cell performance. Results showed that pressure loss in flow channels of hemisphere and triangular cross-sections was much larger than that in rectangular channel, but anode fuel consumption was higher in the former two types of flow field, with higher cell performance obtained. For flow channel width of $1.5 \mathrm{~mm}$, rib width of $0.5 \mathrm{~mm}$ and flow channel depth of $1.5 \mathrm{~mm}$, pressure loss in gas flow was higher due to small width, though the cell performance was better for higher hydrogen consumption. Li et al. [17] discussed the influences of oxygen concentration on PEMFC performance through theoretical analysis and experimental measurement. Their experimental results showed that, at low current density, natural convection and forced convection had similar influences on cell performance. With the increasing of current density, forced convection remained a high output voltage, while for natural convection the cell performance was remarkable degraded. Liu et al. [18] examined the application of the baffle-blocked flow channels for enhancement of reactant transport and cell performance of a proton exchange membrane fuel cell (PEMFC). Due to the blockage effects in the presence of the baffles, more fuel gas in the flow channel can be forced into the gas diffuser layer to enhance the chemical reactions and then augment the performance of the PEMFC systems.

There is little work on the influences of operating conditions on performance of PEM fuel cells with conventional and interdigitated flow field designs, within the literature survey mentioned above. The objective of the present experimental study is to explore the influences of various operating conditions including the cathode inlet gas flow rate, the cathode inlet humidification temperature, and the cell temperature on the cell performance with conventional and interdigitated flow fields.

\section{Principles of flow field designs}

The two flow fields considered in this work are divided into two types, namely conventional and interdigitated flow field designs, as illustrated in Fig. 1. In PEM fuel cells with a conventional flow field, the fuel gas is transported to the diffuser layer mainly by means of diffusion effect; while in the cells with interdigitated flow field, baffles are added at the end of each flow channel to force the fuel gas transported into the diffuser layer by convection, and the shear stress generated by the forced convection can help removing redundant water accumulated in the diffuser layer, thus the limiting current density can be extended. Another issue discussed in this work is the area-ratio effects of the interdigitated flow field. Flow field area ratio is defined as the ratio of the flow field area to the effective reactive area. The flow field area is an important factor that influences the gas transport. 


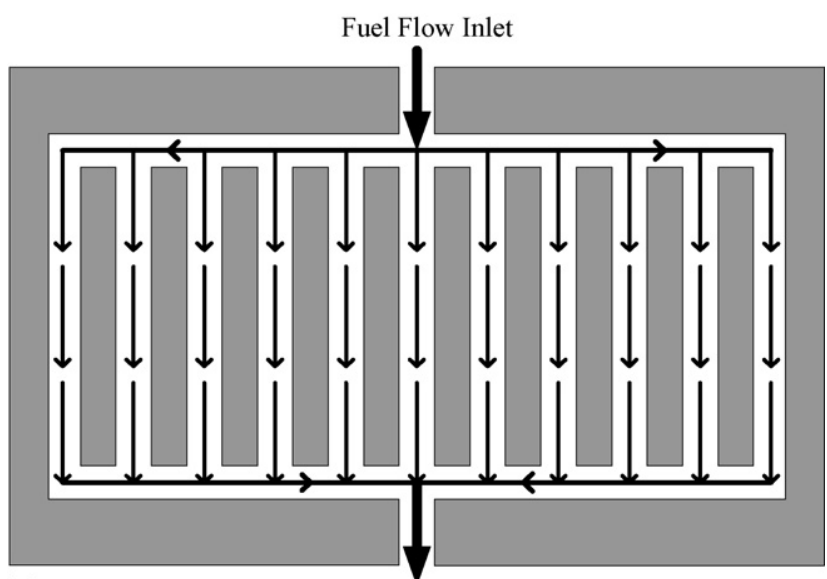

(a)

Fuel Flow Outlet

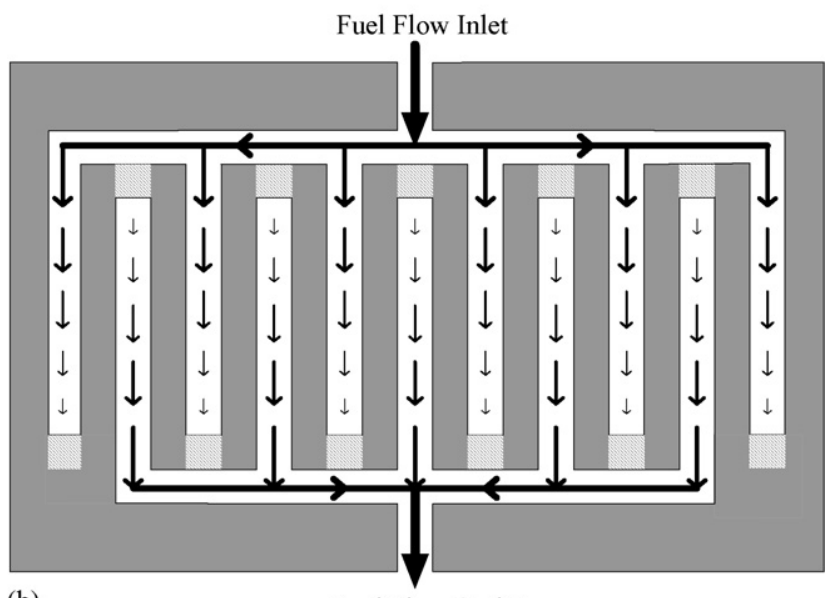

(b)

Fuel Flow Outlet

Fig. 1. Schematic of the tested flow fields: (a) conventional parallel flow field; (b) interdigitated flow field with baffles located at the end of the flow channels.

In interdigitated flow field, larger flow field area implies narrower rib and shorter distance through which the fuel gas travels, thus the fuel gas transport resistance is lower. Another effect of the ribs is to conduct the electricity generated by electrochemical reaction to external circuit loop. The rib width influences the contact resistance. Smaller rib width or higher flow field area ratio may cause excessively high contact resistance between the electrodes and the bipolar plate, and exacerbate ohmic polarization loss of the fuel cell, which is especially remarkable at high current density. Therefore, there should be an optimal value of flow field area ratio.

\section{Experiment setup and methodology}

\subsection{Materials and specifications of PEM fuel cells}

A PEM fuel cell usually consists of seven layers, i.e., cathode flow field plate, cathode gas diffuser layer, cathode catalyst layer, proton exchange membrane, anode catalyst layer, anode gas diffuser layer and anode flow field plate. The structure used in the present experiments, however, is membrane electrode assembly (MEA) of a three-layer structure, including anode and cathode catalyst layers and proton exchange membrane. MEA is the key component in PEM fuel cells. MEA used in the present work is PRIMRA5621 series of GORE-TEX Company and it consists of a proton exchange membrane of $35 \mu \mathrm{m}$ thickness, an anode catalyst with $0.45 \mathrm{~g} \mathrm{~cm}^{2} \mathrm{Pt}$ content, a cathode catalyst with $0.6 \mathrm{~g} \mathrm{~cm}^{2} \mathrm{Pt}$ and $\mathrm{Ru}$ contents, providing a catalyst effective reaction area of $14.1 \mathrm{~cm} \times 14.1 \mathrm{~cm}$. The diffuser layer is made of porous material and mostly employs carbon cloth or carbon paper as main body. The layer has a Teflon film depositing onto it to obtain high hydrophobicity for reducing liquid water accumulation inside. The diffuser layer used in experiments is GORE-TEX PRIMRA5621 with thickness of $400 \mu \mathrm{m}$ and size of $14.1 \mathrm{~cm} \times 14.1 \mathrm{~cm}$. Bipolar plates (POCO company) made of pure graphite with thickness of $3 \mathrm{~mm}$ are used in the experiments for fuel gas and electric transport. The current collector plate is made of rose copper with area of $22 \mathrm{~cm} \times 22 \mathrm{~cm}$ and thickness of $0.4 \mathrm{~cm}$, and plated with a gold film on its surface to avoid erosion and to reduce contact resistance. End plates located at the outmost of the fuel cell bound all of the layers in the fuel cell with a homogeneous stress. The end plates are of $26 \mathrm{~cm} \times 26 \mathrm{~cm}$ in area and $2 \mathrm{~cm}$ in thickness, made of aluminum alloy 7075 with its surface anodized for insulation.

\subsection{Experimental setup}

Fig. 2 shows schematically the fuel cell test facility consisting of five major parts, i.e., gas supply system, flow rate control system, temperature control system, humidity system and electric load system. The gas supply system supplies hydrogen and oxygen (or air) as the anode and cathode reactant gas, respectively. Nitrogen gas is supplied to purge the residual gas inside the cell before and after each test. The flow rate control system controls the gas inlet flow rate following stoichiometry and minimum flow method. As for the temperature control system, heating rod, type-T thermocouples and temperature controller (CN760000) are employed to modulate the internal temperature of the fuel cell. The humidification system modulates the gas humidification by adjusting the temperature of the humidification bottles. The electric load system enables the maximum power output of $600 \mathrm{~W}$, the maximum voltage of $60 \mathrm{~V}$ and the maximum current of $120 \mathrm{~A}$ (Table 1).

\section{Results and discussion}

\subsection{Influences of the cathode inlet fuel on fuel cell performance}

Performance of PEM fuel is characterized by $I-V$ curve and is closely related to the fuel flow rates in cathode and anode. For the cases of high current density, in contrast, larger fuel flow rates in cathode and anode are required. In this work, the supplied anode hydrogen flow rate is fixed to solely investigate the influence of the cathode inlet fuel on the cell performance. Thus, if the cell performance is enhanced with the increasing cathode fuel gas, it implies that the anode hydrogen is not completely consumed. Contrarily, if the cell performance remains constant, it implies that the anode hydrogen is completely con- 


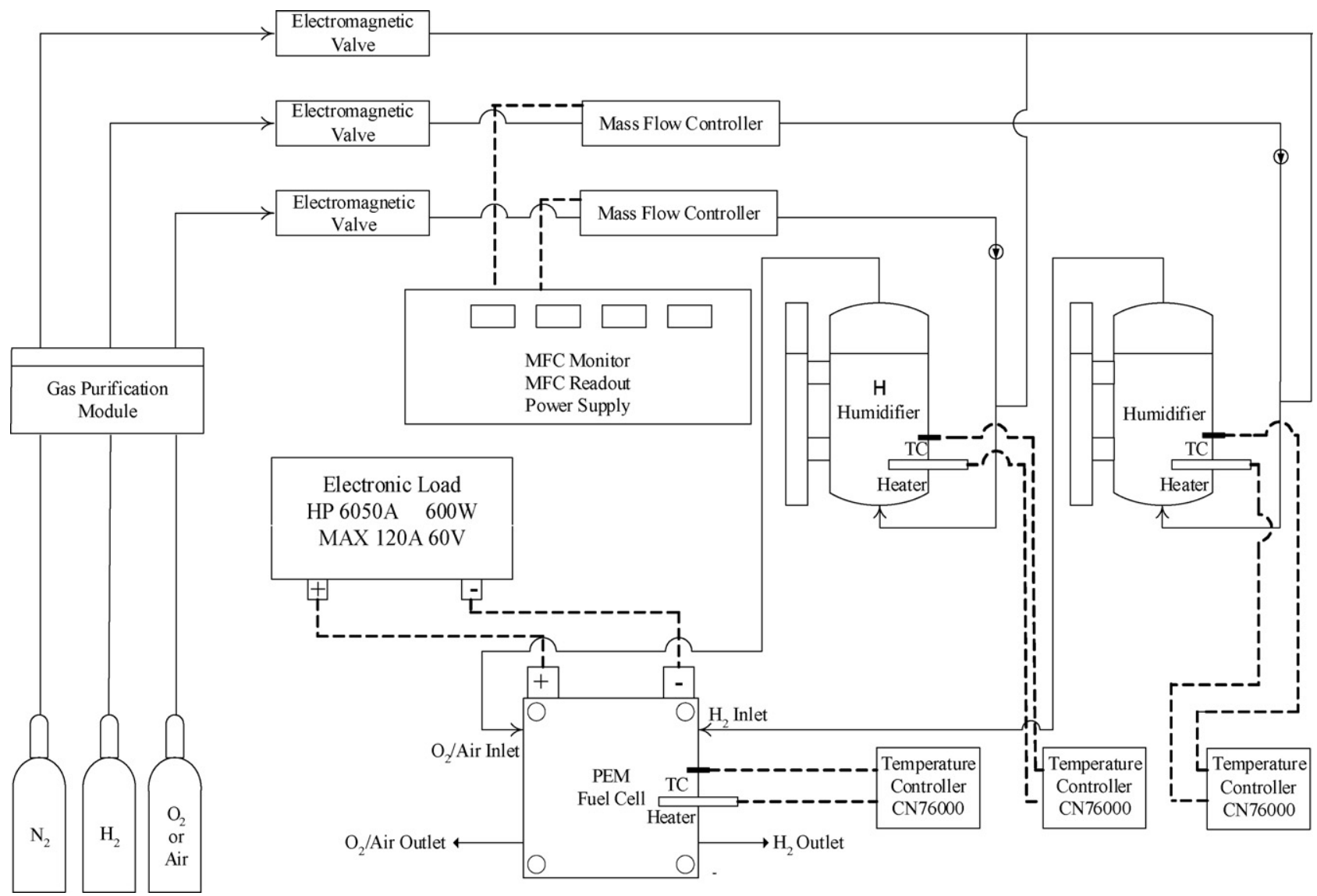

Fig. 2. Schematic diagram of the experimental setup.

sumed, while the cathode fuel is excess. It is worth noting that in the study of PEMFC, the volume flow rate of anode hydrogen is an important parameter on the cell performance. The effects of the volume flow rate of anode hydrogen on the cell performance would be examined in the near future.
Fig. 3 shows the influences of oxygen flow rate on $I-V$ curves of the fuel cell. Fig. 3(a) indicates that, as oxygen flow rate increases from 1000 to $2000 \mathrm{~cm}^{3} \mathrm{~min}^{-1}$ in fuel cell with conventional flow field, the $I-V$ curves performance is obviously enhanced with an increase in oxygen flow rate. However, as the

Table 1

Operating parameters and conditions used in this work

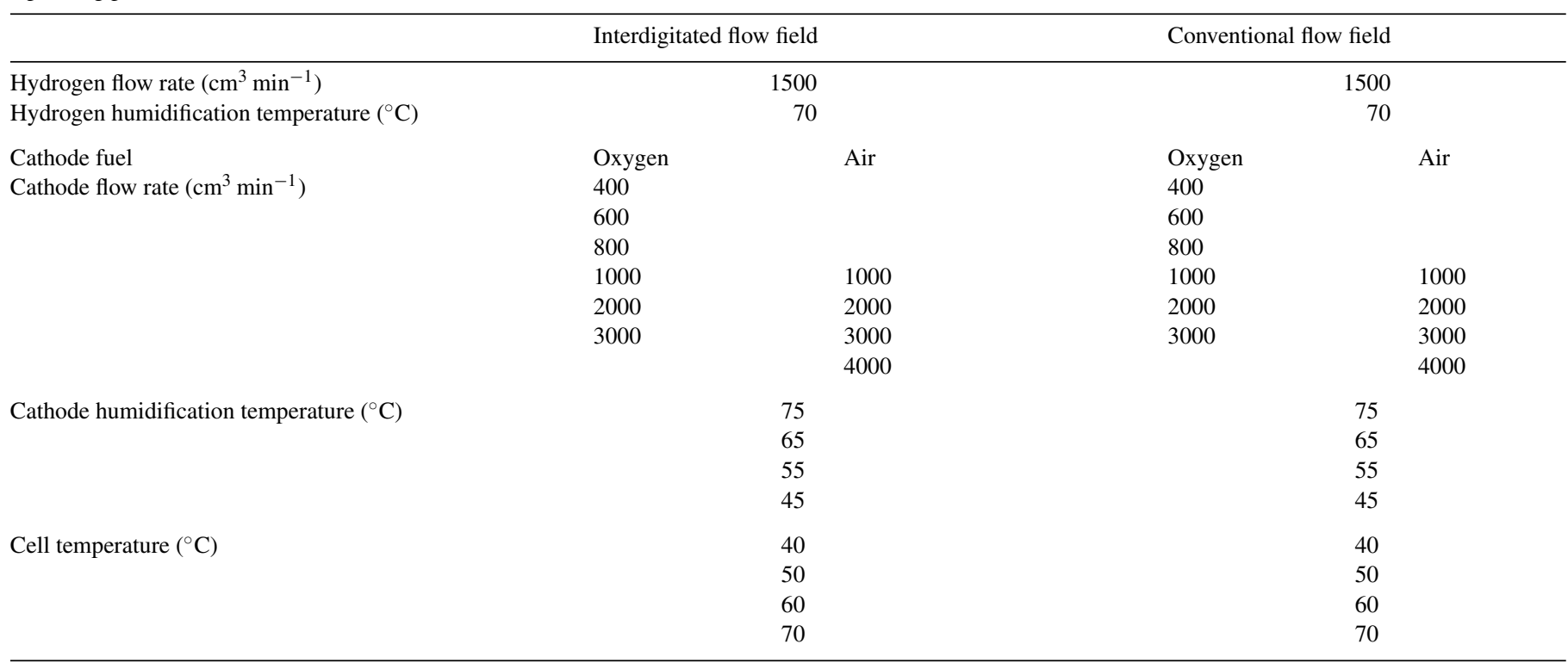



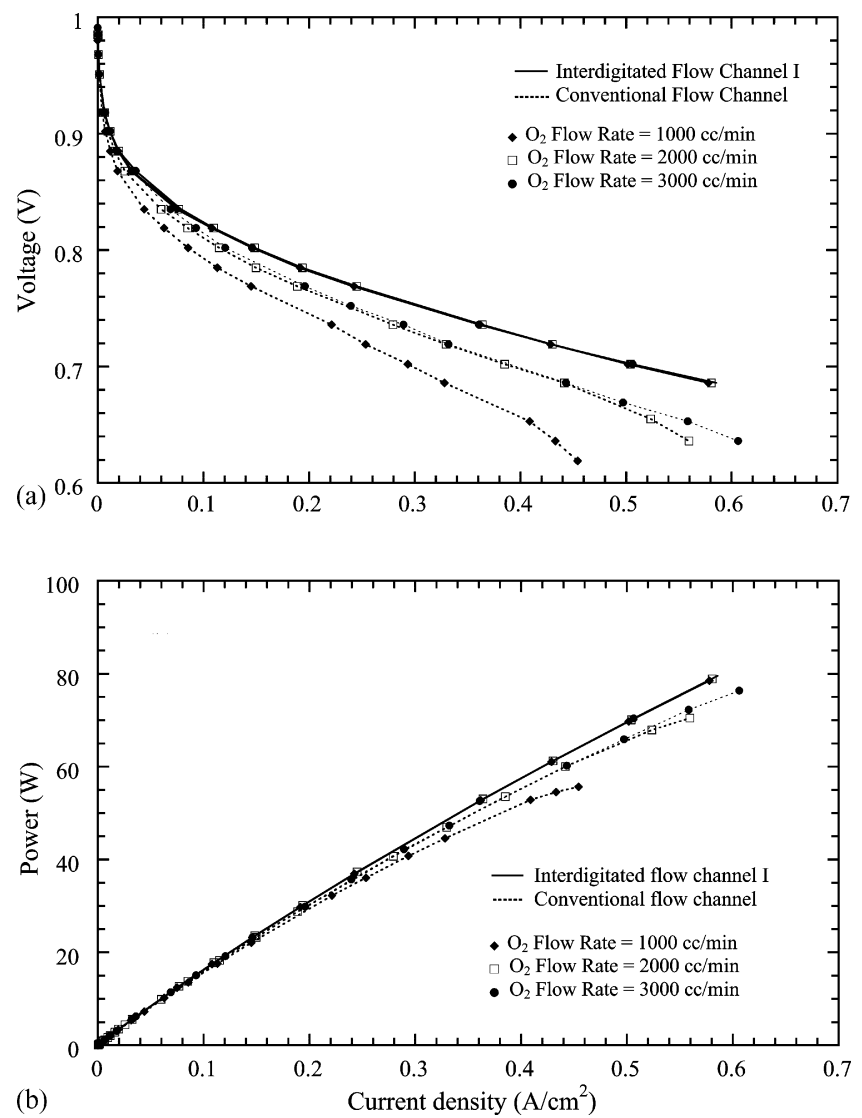

Fig. 3. Effects of flow field design and oxygen fuel flow rate on the cell performance of PEM fuel cells: (a) $I-V$ curves; (b) $I-P$ curves.

flow rate is beyond $2000 \mathrm{~cm}^{3} \mathrm{~min}^{-1}$, increasing oxygen flow rate has little effect on the cell performance, except for the current density higher than $0.5 \mathrm{~A} \mathrm{~cm}^{2}$, at which obvious difference can be observed. The reason lies in that, at oxygen flow rate of $1000 \mathrm{~cm}^{3} \mathrm{~min}^{-1}$, lower cell performance is obtained for incomplete consumption of the anode hydrogen. Whereas as oxygen flow rate lying below $2000 \mathrm{~cm}^{3} \mathrm{~min}^{-1}$ and the current density below $0.5 \mathrm{~A} \mathrm{~cm}^{2}$, the oxygen supplied at the cathode is adequate to completely consume hydrogen at the anode, thus increasing oxygen flow rate will not enhance the cell performance at a constant hydrogen flow rate. Thereby, if the current density is below $0.5 \mathrm{~A} \mathrm{~cm}^{2}$, equivalent cell performance will be achieved at oxygen flow rates of 2000 and $3000 \mathrm{~cm}^{3} \mathrm{~min}^{-1}$. While at high current density (e.g., $I>0.5 \mathrm{~A} \mathrm{~cm}^{2}$ ), due to the increase of the current density, oxygen flow rate required at the cathode gradually exceeds the supplied oxygen flow rate, thus the cell performance at oxygen flow rate of $2000 \mathrm{~cm}^{3} \mathrm{~min}^{-1}$ is lower than that at $3000 \mathrm{~cm}^{3} \mathrm{~min}^{-1}$. Fig. 3(b) shows the same trend. If the cathode flow field is interdigitated with channel area ratio of $50.75 \%$, it can be discovered that an oxygen flow rate of $1000 \mathrm{~cm}^{3} \mathrm{~min}^{-1}$ can completely consume hydrogen supplied at the anode. The cell performance will remain constant without being influenced by increasing flow rate, and the cell performance has little discrepancy at the flow rates of 1000, 2000 and $3000 \mathrm{~cm}^{3} \mathrm{~min}^{-1}$. For the interdigitated flow field at flow rate lower than $1000 \mathrm{~cm}^{3} \mathrm{~min}^{-1}$, it is found that, in the separate
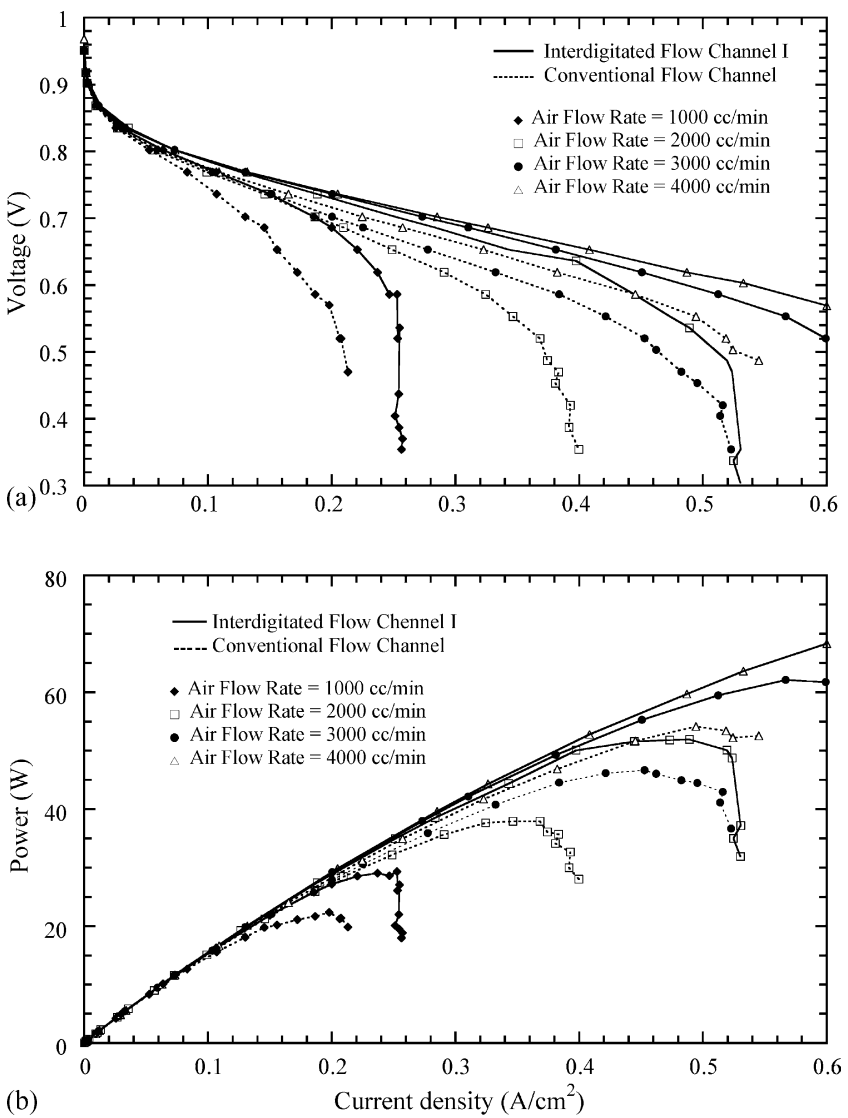

Fig. 4. Effects of flow field design and air fuel flow rate on the cell performance of PEM fuel cells: (a) $I-V$ curves; (b) $I-P$ curves.

experimental runs, the cell performs approximately the same at the oxygen flow rates higher than $600 \mathrm{~cm}^{3} \mathrm{~min}^{-1}$. At an oxygen flow rate of $400 \mathrm{~cm}^{3} \mathrm{~min}^{-1}$, the low oxygen flow rate causes the cell performance decayed at higher current density owing to deficient oxygen supply. Oxygen content in the air is about $1 / 5$, thus the cell performance with air as the cathode fuel gas is always worse than that with oxygen. Fig. 4 shows the influences of oxygen flow rate on $I-V$ curves and power curves of the fuel cell. Taking conventional flow field as the example, the $I-V$ curves in Fig. 4(a) show enhanced performance with the increase in the flow rate of air. Fig. 4(b) also interprets that, at flow rate of $1000 \mathrm{~cm}^{3} \mathrm{~min}^{-1}$, the limit current density and the optimal power are around $0.22 \mathrm{~A} \mathrm{~cm}^{2}$ and $22 \mathrm{~W}$, respectively. As the flow rate increases from 1000 to $3000 \mathrm{~cm}^{3} \mathrm{~min}^{-1}$, the limit current density and the optimal power will evidently increase to $0.52 \mathrm{~A} \mathrm{~cm}^{2}$ and $47 \mathrm{~W}$, respectively. By comparing Fig. 3 with Fig. 4, it is found that, in conventional flow field, an oxygen flow rate higher than $3000 \mathrm{~cm}^{3} \mathrm{~min}^{-1}$ is adequate to completely consume the anode hydrogen. However, with air at flow rate lower than $4000 \mathrm{~cm}^{3} \mathrm{~min}^{-1}$, the cathode oxygen cannot completely consume the anode oxygen, and the cell performance can be enhanced remarkably by increasing air flow rate. It can be concluded from above results that, if oxygen is not sufficient for consuming hydrogen, increasing oxygen flow rate will effectively improve the cell efficiency; while as the oxygen sufficiently supplied, further increasing oxygen at cathode is no 
more beneficial to the cell efficiency. This fact implies that in practical operation of fuel cell the fuel flow rate should be appropriately chosen for high efficiency as well as for avoiding waste of fuels. It is worth noting that in the present study, the data of the $I-V$ curves are always steady. Therefore, the polarization curves are steady-state values and are not the time-averaged values.

\subsection{Influences of the cathode inlet temperature on fuel cell performance}

In PEM fuel cells, water content in PEM has an impact on the membrane conductivity. Higher water content leads to higher membrane conductivity; in contrast, a lack of water content in the membrane will cause performance degradation due to dehydration. Thus, the cathode and anode are humidified during operation of the fuel cell, requiring temperatures higher than the cell temperature. To determine the cathode and anode temperatures, the cathode inlet temperature is fixed $5^{\circ} \mathrm{C}$ higher than the cell temperature and the anode inlet temperature $10^{\circ} \mathrm{C}$ higher in experiments. Fig. 5 shows the influences of different inlet oxygen temperatures on the cell performance for conventional flow field and interdigitated flow field with area ratio of $50.75 \%$. The cell performance becomes better with the increase of the inlet oxygen temperature. In a PEM fuel cell, gas humidification is to increase water content in membrane electrodes and thus to improve hydrogen ion transport in membrane electrodes. Consequently, increasing the cathode inlet temperature is beneficial to the electron transport and in turn enhances the cell performance. In addition, at the same cathode inlet temperature, better cell performance is noted for the PEMFC with interdigitated flow field due to both the effects of the enhanced oxygen concentration at catalyst sites due to convection and the enhanced removal of liquid water in gas channels and MEA due to the increased pressure drop.

Fig. 6 shows the influences of inlet air temperature on $I-V$ curves with air as the cathode inlet gas. The data indicate that the cell performance is elevated with the increase of inlet air temperature at low current density, i.e., $I<0.33 \mathrm{~A} \mathrm{~cm}^{2}$ for conventional flow field and $I<0.4 \mathrm{~A} \mathrm{~cm}^{2}$ for interdigitated flow field with area ratio of $55.75 \%$. While at high current density, the inlet

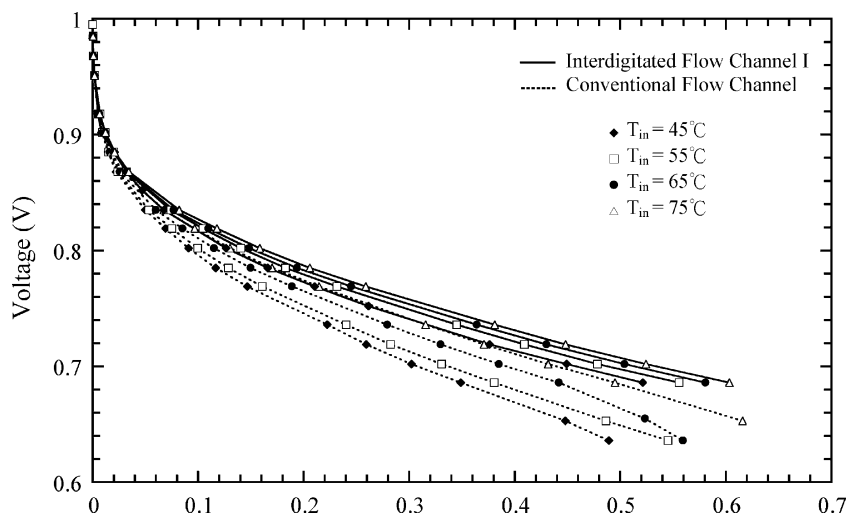

Fig. 5. Effects of flow field design and oxygen humidification temperature on the cell performance of PEM fuel cells.

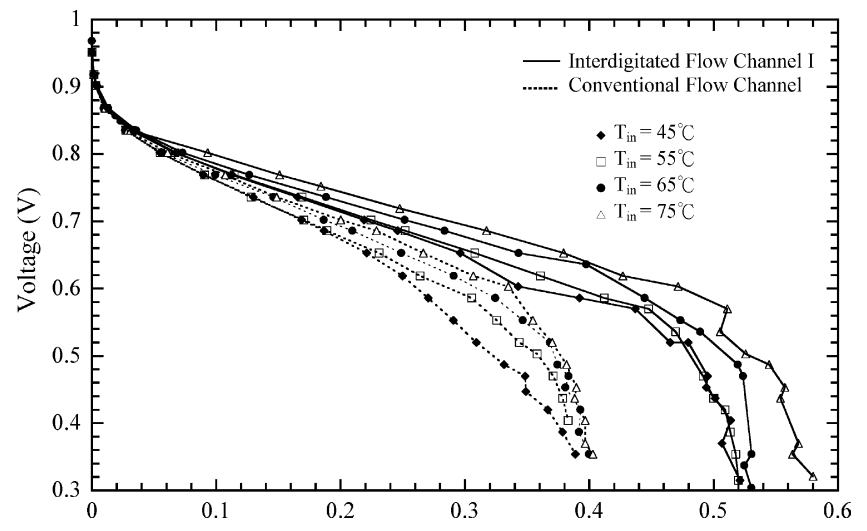

Fig. 6. Effects of flow field design and air humidification temperature on the cell performance of PEM fuel cells: $I-V$ curves.

air temperature has little effect. The reason is that oxygen contained in the air in the flow field is completely consumed and is accordingly deficient at the catalyst surface at high current density, resulting in fluctuation in $I-V$ curves and power curves.

\subsection{Influences of cell temperature on the cell performance}

Increasing the cell performance is helpful to enhance electrochemical reaction rate and ionic transport in PEM, and accordingly the cell performance. However, the cell temperature should not be higher than $90^{\circ} \mathrm{C}$, or PEM may be damaged due to overheating. From the results shown in Fig. 7, it is observed that, as the cell temperature increased from 40 to $60^{\circ} \mathrm{C}$, the cell performance is enhanced; the worst cell performance, however, is presented at the cell temperature of $70^{\circ} \mathrm{C}$. The reason lies in that, as the cell temperature increases from 40 to $60^{\circ} \mathrm{C}$, the cell temperature is lower than the cathode and anode inlet temperatures, resulting in accelerated electrochemical reaction and enhanced the cell performance. As the cell temperature is over $70^{\circ} \mathrm{C}$, which is equal to the anode inlet temperature and higher than the cathode inlet temperature, the cathode and anode inlet gases are not able to effectively humidify the cell but take away the water in the cell.

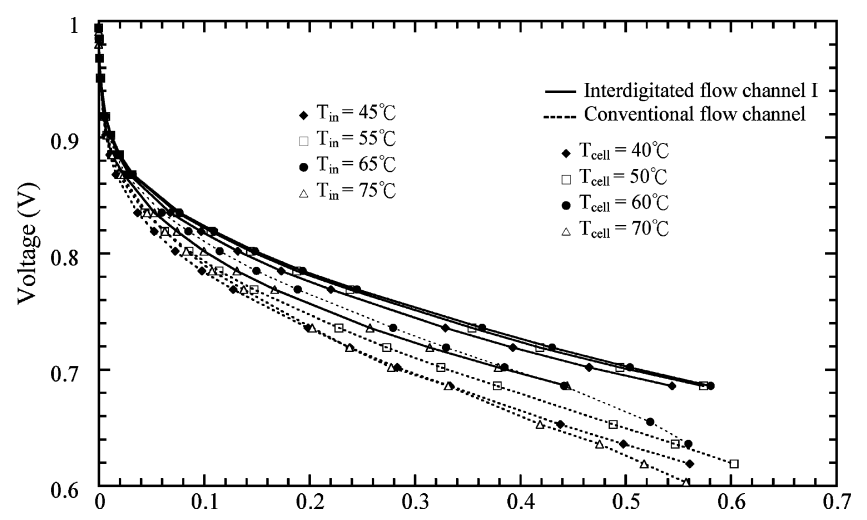

Fig. 7. Effects of flow field design and cell temperature on the cell performance of PEM fuel cells with oxygen being cathode fuel. 


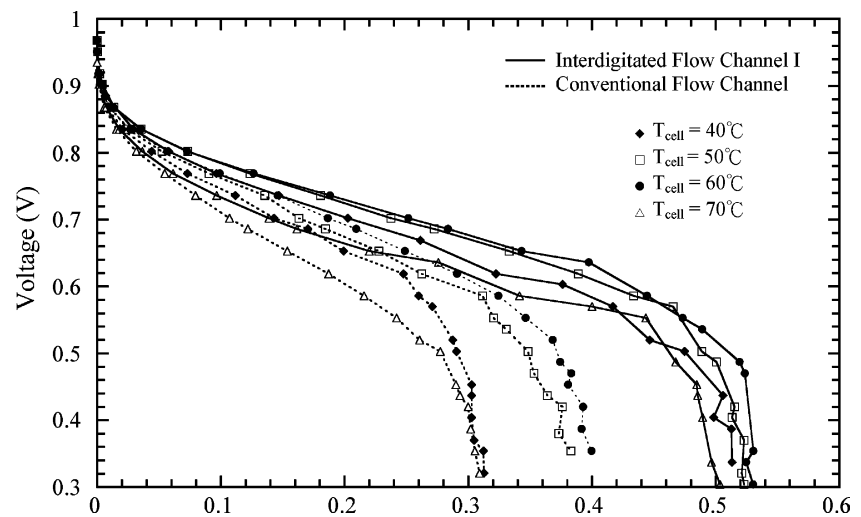

Fig. 8. Effects of flow field design and cell temperature on the cell performance of PEM fuel cells with air being cathode fuel.

Fig. 8 shows the influences of the cell temperature on the performance curves for the cases with air as the cathode inlet gas. At low current density, similar results are obtained as depicted in Fig. 7, which shows the worst cell performance at the cell temperature of $70^{\circ} \mathrm{C}$. As the cell temperature increasing from 40 to $60^{\circ} \mathrm{C}$, the performance is enhanced. Similarly, at a high current density, because of deficient oxygen content in the air at cathode, fluctuation appears in $I-V$ curves, as shown in Figs. 4 and 6.

\subsection{Influences of three cathode flow field designs on fuel cell performance}

The influences of three different cathode flow field designs on the fuel cell performance are examined. Fig. 9 shows the influences of the cathode inlet flow rate on cell performance of the three flow fields with oxygen as the cathode inlet gas. It can be concluded from Fig. 9(a) that, at various operating conditions considered, the interdigitated flow field with area ratio of $50.75 \%$ always results in the highest cell performance, due to the effective transport of fuel gas and the lower internal resistance. The situation with conventional flow field, on the other hand, is quite different. At low flow rate, e.g., flow rate $<1000 \mathrm{~cm}^{3} \mathrm{~min}^{-1}$, the supplied oxygen can not completely consume the anode hydrogen in conventional flow field, thus better cell performance will be obtained in interdigitated flow field with flow field area ratio of $66.67 \%$. While at a high flow rate such as the flow rate $\geqq 2000 \mathrm{~cm}^{3} \mathrm{~min}^{-1}$, the conventional flow field leads to higher performance due to lower internal resistance than interdigitated flow field with flow field area ratio of $66.67 \%$.

Fig. 10 shows the influences of the cathode inlet flow rate on cell performance with air as the cathode inlet gas. In Fig. 10(a), it is indicated that the interdigitated flow field with area ratio of $50.75 \%$ results in the highest performance; but at low current density, there is no evident discrepancy between the interdigitated flow field with area ratio of $66.67 \%$ and the conventional flow field; yet at high current density, better cell performance can be obtained in interdigitated flow field with area ratio of $66.67 \%$ over the conventional flow field. With air as the inlet gas, interdigitated flow field is advantageous for fuel gas transport and extension of the limit current density. Consequently, it can be discovered in Fig. 10(b) that the cell performance and the limit
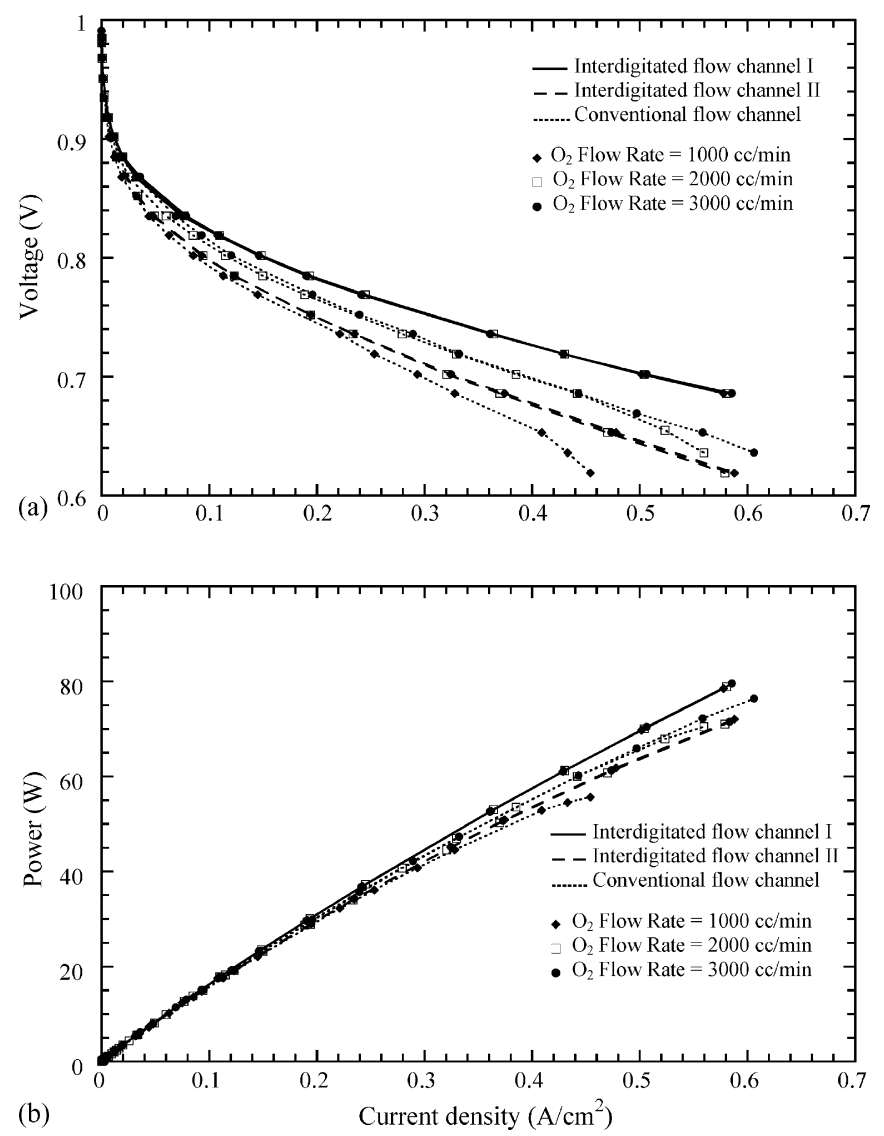

Fig. 9. Comparison of the cell performance of PEM fuel cells among three flow field design with oxygen as cathode fuel.

current density in interdigitated flow field with flow field area ratio of $50.75 \%$ are more favorable than those in conventional flow field. As for comparison of interdigitated flow field with area ratio of $66.67 \%$ to the conventional flow field, the former can effectively increase the flow rate of gas entering the diffuser layer, while the latter has a lower internal resistance. There is no obvious difference between the two flow fields at low current density; while at high current density, cell performance with the interdigitated flow field is higher than that with conventional flow field due to delayed occurrence of the limit current density in the former one.

The results in Figs. 1, 5 and 7 show that the cell performance of interdigitated flow field is 1.1 times as that of conventional flow field. It can be figured out by investigating Fig. 3(b) that the output powers of the conventional flow field and the interdigitated flow field are 66 and $70 \mathrm{~W}$, respectively. Such a discrepancy is raised because that interdigitated flow field can effectively increase gas entering the diffuser layer, leading to better performance than conventional flow field. Comparison between Figs. 4, 6 and 8 also shows that, with air as the inlet gas, interdigitated flow field can enhance the cell performance and also delay the occurrence of the limit current. As the basic operating parameters considered, the limit current $0.4 \mathrm{~A} \mathrm{~cm}^{2}$ in conventional flow field is increased to $0.53 \mathrm{~A} \mathrm{~cm}^{2}$ in interdigitated flow field and the optimal power $38 \mathrm{~W}$ is enhanced to $52 \mathrm{~W}$ by a factor of 1.37 . 

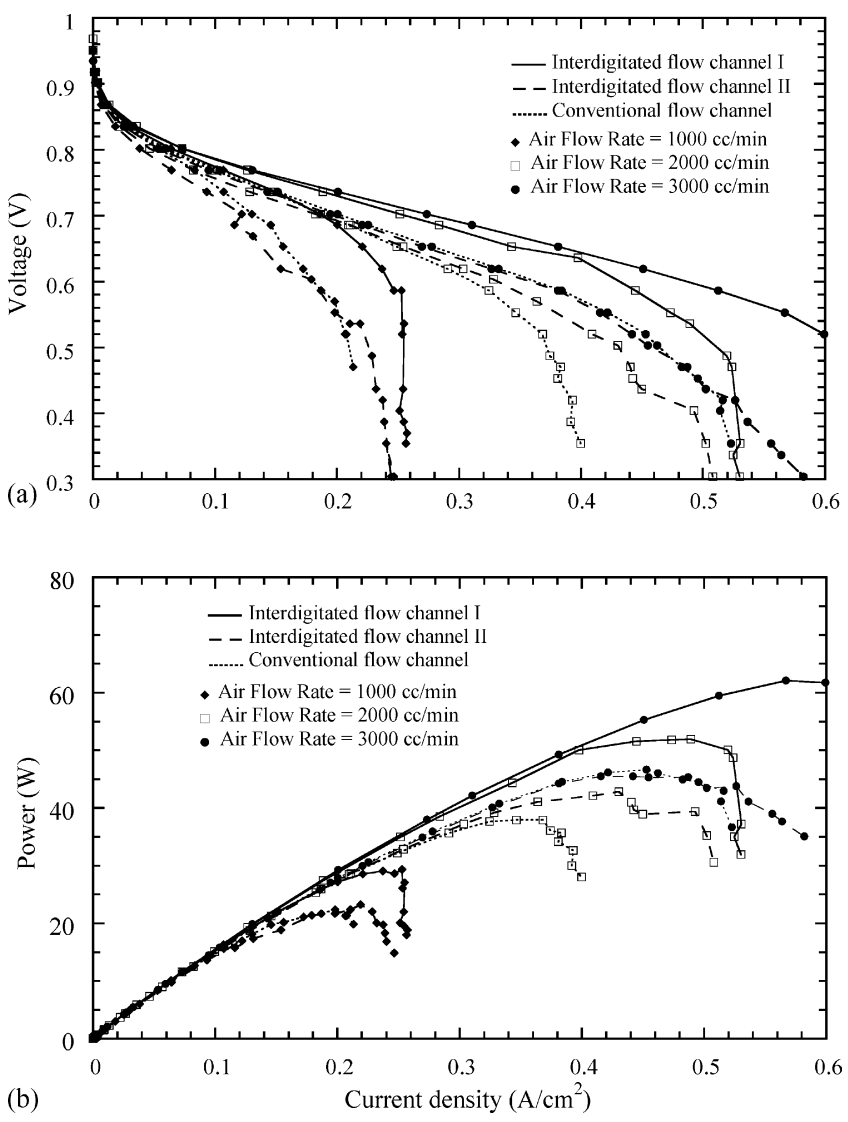

Fig. 10. Comparison of the cell performance of PEM fuel cells among three flow field design with air oxygen as cathode fuel.

\section{Conclusions}

In the present work, experiments were conducted to explore the influences of various operating conditions including cathode inlet gas flow rate, cathode inlet humidification temperature, cell temperature on the performance of PEM fuel cells with convention and interdigitated flow fields. Based on above experimental results, the following conclusions can be drawn:

1. Under the operating conditions considered, the cell performance is enhanced with the increase in cathode inlet gas flow rate, cathode inlet humidification temperature and cell temperature. However, the cell temperature should not be higher than or equal to the anode inlet gas temperature, otherwise the cell performance will be deteriorated owing to failure in humidification.

2. Comparing interdigitated flow field with conventional flow field at the area ratio of $50.75 \%$, it is found that the interdigitated flow field is advantageous at economizing fuel consumption. Interdigitated flow field at flow rate of
$600 \mathrm{~cm}^{3} \mathrm{~min}^{-1}$ performs better than conventional flow field at flow rate of $3000 \mathrm{~cm}^{3} \mathrm{~min}^{-1}$, indicating that the former can enhance cell performance and also reduce fuel consumption.

3. For the cases with air as the cathode inlet gas, interdigitated flow field can effectively extend the limit current density and provide higher cell power. As a result, the maximum power of interdigitated flow field is about 1.4 times as that of conventional flow field.

4. Rib and shoulder areas are more advantageous to electrochemical reaction in interdigitated flow field; hence larger flow field area ratio decreases the area with better cell performance. But too low a flow field area ratio deteriorates the cell performance due to the decrease in effective reaction area. Theoretically, there is an optimum value of flow area. In this work, interdigitated flow field of the area ratio of $50.75 \%$ performs better than that of $66.67 \%$.

\section{Acknowledgements}

The study was supported by the National Science Council, the Republic of China, through the grants NSC 93-2212-E-211-011, NSC 92-2623-7-002-006-ET and NSC 92-2212-E-002-096.

\section{References}

[1] P.L. Hentall, J.B. Lakeman, G.O. Mepsted, P.L. Adcock, J.M. Moore, J. Power Sources 80 (1999) 235-241.

[2] T.V. Nguyen, J. Electrochem. Soc. 143 (1996) L103-L105.

[3] D.L. Wood, J.S. Yi, T.V. Nguyen, Electrochim. Acta 43 (1998) 3795-3809.

[4] W. He, J.S. Yi, T.V. Nguyen, AIChE J. 46 (2000) 2053-2064.

[5] J.S. Yi, T.V. Nguyen, J. Electrochem. Soc. 146 (1999) 38-45.

[6] T.V. Nguyen, R.E. White, J. Electrochem. Soc. 140 (1993) 2178-2186.

[7] H.K. Choi, H.D. Peck, S.C. Kim, R.D. Shin, J. Power Sources 86 (2000) 197-201.

[8] P.W. Li, L. Schaefer, Q.M. Wang, T. Zhang, M.K. Chyu, J. Power Sources 115 (2003) 90-100.

[9] S. Um, C.Y. Wang, Proceedings of the ASME Fuel Cell Division, the 2000 ASME Int. Mech. Engng. Congress \& Exposition, Orlando, FL, 2000.

[10] A. Kazim, H.T. Liu, P. Forges, J. Appl. Electrochem. 29 (1999) 1409-1416.

[11] E. Hontanon, M.J. Escudero, C. Bautista, P.L. Garcia-Ybarra, L. Daza, J. Power Sources 86 (2000) 363-368.

[12] S. Dutta, S. Shimpalee, J.W. Van Zee, Int. J. Heat Mass Transfer 44 (2001) 2029-2042.

[13] P.T. Nguyen, T. Berning, N. Djilali, J. Power Sources 130 (2004) 149-157.

[14] H. Dohle, A.A. Kornyshev, A.A. Kulikovsky, J. Mergel, D. Stolten, Electrochem. Commun. 3 (2001) 73-80.

[15] W.M. Yan, C.Y. Soong, F. Chen, H.S. Chu, J. Power Sources 125 (2004) 27-39.

[16] A. Kumar, R.G. Reddy, J. Power Sources 113 (2003) 11-18.

[17] P.W. Li, T. Zhang, Q.M. Wang, L. Schaefer, M.K. Chyu, J. Power Sources 114 (2003) 63-69.

[18] H.C. Liu, W.M. Yan, C.Y. Soong, F. Chen, J. Power Sources 142 (2005) 125-133. 